\title{
Analysis of the Implementation of Monitoring and Evaluation by Presidential Staff Office in Infrastructure Delivery

\author{
Muhammad Emmir ${ }^{1}$, Vishnu Juwono ${ }^{2 *}$
}

\author{
${ }^{1}$ Faculty of Administrative Science, Universitas Indonesia \\ ${ }^{2}$ Faculty of Administrative Science, Universitas Indonesia \\ ${ }^{*}$ Corresponding author. Email: vjuwono@ui.ac.id
}

\begin{abstract}
This study discusses the implementation of monitoring and evaluation mandated by the Presidential Staff Office (KSP) in the implementation of infrastructure. The purpose is to analyze KSP's application of results-based monitoring and evaluation of infrastructure implementation. The results-based monitoring and evaluation (monev) theory are applied because the scope of KSP monev arrived at the benefits/impacts, resulting in dari infrastructure projects. The research employs a descriptive-qualitative method by referring to the post-positivist paradigm with an operationalization of the concept. The critical representation of the infrastructure program during the administration of President Joko Widodo is the National Strategic Project. Of the 200 PSN that have been set as targets for completion, as of 2019, fewer than half were completed. Meanwhile, KSP's implementation of monitoring and evaluation is an effort to succeed in the National Priority Program, which should be boosted by infrastructure development. The results-based monev analysis shows that there are still problems in the management of results-based monev in the KSP, along with issues of overlapping authority between K/L that carry out monitoring and evaluation. These problems cause the monitoring and evaluation to be ineffective, resulting in the slow realization of PSN. The recommendation in this study is to improve KSP's management of monitoring and evaluation by following resultsbased monev guidelines and reforming business processes. This study contributes insights into monev governance in the implementation of effective and efficient infrastructure development.
\end{abstract}

Keywords: Results-Based Monitoring and Evaluation, Infrastructure, Presidential Staff Office

\section{INTRODUCTION}

Infrastructure is an essential requirement for a country to have if it is to be categorized as a developed nation. Economic actors' use of infrastructure can provide opportunities for them to reap huge profits, because production costs can be minimized by the availability of manufacturing facilities and distribution activities can be reduced through the use of connectivity infrastructure, such as roads, bridges, and so on. The convenience of investing in infrastructure in Indonesia has caught the attention of investors, so that the number of investors is rising. This is a favorable effect of the implementation of infrastructure. The argument is reinforced by the opinion (Gie, 2002) that the availability of infrastructure services reduces production costs. The life of the community also depends on fulfilling the needs of electricity, clean water, food, and fuel for vehicles, which can only be achieved if appropriate infrastructure is available.

The implementation of infrastructure needs to be supervised to ensure that project developments run smoothly according to the president's vision and mission. Supervision begins in the planning process and continues throughout the construction process, so that the quality of infrastructure can be ensured to meet the citizen demand. The argument was strengthened in the National Development Planning Agency document titled "Development Monitoring and Control Improving the Quality of Development" (Bappenas, Workshop, and Opening of the Monitoring Period in 2019, 2019). The main goal of infrastructure development is to 
achieve the targets of physical growth and human development.

The government issued several Presidential Regulations, which assigned several $\mathrm{K} / \mathrm{L}$ to control, monitor, and implement the acceleration of the National Priority Program. The $\mathrm{K} / \mathrm{L}$ is the Office of the Presidential Staff, Financial and Development Supervisory Agency, National Development Planning Agency, and Cabinet Secretary (Tempo.co, 2015).

The president has issued related regulations, including Presidential Regulation No. 192 of 2014 regulating the BPKP; Presidential Regulation No. 25 of 2015, which governs the Cabinet Secretariat; Presidential Regulation No. 20 of 2016 concerning Bappenas; and Presidential Regulation No. 26 of 2015, which regulates the Presidential Staff Office (KSP). Of these four regulations, only the KSP presidential regulation explicitly covers the function of monitoring, evaluating, and accelerating the implementation of the National Priority Program. It is known that the application of infrastructure, such as the National Strategic Project (PSN), is one of the 10 National Priority Programs.

However, it should be noted that KSP's authority in monitoring the National Priority Program is primarily already been done by existing monitoring and evaluation institutions such as the Coordinating Ministry for Economic Affairs. The objects monitored by the Coordinating Ministry for Economic Affairs cover all government programs, including national priority programs in the economy. Thus, it can be said that the National Priority Program is only a small part of government programs. As one KPPIP official said,

"We [KPPIP] are coordinating our friends to be able to compile the status of this PSN, because KPPIP has members from a number of ministries: the leading ministry from the Coordinating Ministry of Economic Affairs, and below that, other ministries in charge of issue licensing, which includes the Ministry of Finance, Ministry of Forestry, and State Minister of Planning (Bappenas). After that, the technical and mechanism is determined. So, for example, we monitor PSN through Assistant Deputies within six ministries in the area of economy, that are in charge of infrastructure." (Interview with Ahdi, KPPIP employee, May 14, 2019)

As can be seen clearly, there is overlapping in the monitoring and evaluation of infrastructure and PSN programs. KPPIP monitors the management of PSN projects. So, even though KSP is a unique institution that monitors priority infrastructure programs and PSN, the existence of the Coordinating Ministry for Economic Affairs and KPPIP mean that the specificity of the KSP cannot be justified. The fulfillment of the second indicator can still be debated given the presence of the Coordinating Ministry for Economic Affairs and
KPPIP. There should be only one designated institution that monitors and evaluates infrastructure, to avoid redundancy between KSP and the Coordinating Ministry for Economic Affairs/KPPIP.

Infrastructure development is part of President Joko Widodo's National Priority Program; and KSP is tasked with monitoring and evaluation in the implementation of infrastructure development programs. Presidential Regulation No. 26 of 2015, Article 3, Section (a) states that KSP has the role "to monitor to ensure national priority programs are carried out following the President's vision and mission." Then, Section (d) describes that KSP has he role "to monitor to ensure progress toward the implementation of national priority programs." The existence of the KSP Perpres strengthens the selection of KSP as the locus of this study.

Every day, KSP receives 389 complaints related to infrastructure (Jawa Pos, 2016), and 14 accidents have occurred in a total of over 200 PSN (BBC News Indonesia, 2018). The number of infrastructure project accidents has slowed the development of infrastructure. Based on information given by the Committee for the Acceleration of Priority Infrastructure, among the infrastructure projects started in 2016 to 2019, only 68 projects can be completed. KPPIP itself acknowledges that the objective of 68 projects is still very far from the government's expectations, where the actual target is 200 more (Safrezi, Fitra. Katadata, 2018).

Public complaints about infrastructure, project accidents, and the slow realization of National Strategic Projects can raise the question of how KSP carries out the mechanism of monitoring and evaluating infrastructure implementation. Since KSP is in charge of supervising and controlling the progress of infrastructure development as a National Priority Program launched by the president, its responsibility is to maintain the president's program, in this case, infrastructure/PSN, so that the development will proceed smoothly to produce quality infrastructure according to the vision and mission stated in Presidential Regulation No. 26 of 2015. Based on the experience of a researcher visiting KSP and as explained earlier that KSP has a special team tasked with monitoring and evaluating infrastructure development, namely, the infrastructure unit under the KSP Deputy I, the function of monitoring and evaluation is closely related to monitoring activities. Apart from various existing infrastructure problems, there are several reports that KSP carries out its duties to monitor infrastructure development.

There is a report stating that the Chief of KSP, Moeldoko, oversees the construction process of the Makassar Port of New Port (Agustian, Widi. Okefinance, 2018). Moeldoko, as the Head of KSP, also 
conducted a review/monitoring of development in many infrastructure projects.

In addition to conducting monitoring and evaluation functions, the Presidential Staff Office also performs its monitoring function through the LAPOR website portal. LAPOR is an online public complaint system that provides KSP reports regarding community complaints about existing infrastructure projects. It can accommodate community complaints that inform of stalled/problematic infrastructure projects. After complaints are supplied in the LAPOR database, the data are disseminated to the ministries or government agencies that are the subject of the complaint so that they could respond immediately.

If KSP finds a problem in infrastructure management after carrying out field visits and receiving a report from LAPOR, for instance, then it has the right to conduct debottlenecking. This means removing obstacles that slow the implementation of a project. Regarding technical debottlenecking, KSP implements it by following up on the problems that are slowing the project development. KSP invites all specific project stakeholders to a coordination meeting to discuss what issues pose obstacles to the construction process and what solutions can be found (Gumilang, 2018).

KSP faces numerous challenges in monitoring and evaluating infrastructure implementation, including problems that occur in the implementation of PSN infrastructure. Several PSN projects have been damaged, and some community grievances have been raised related to the infrastructure. Unfortunately, the economic data show that the infrastructure/PSN was not able to increase the GDP significantly. Therefore, the purpose of this research is to analyze the implementation of the monitoring and evaluation process in the PSN infrastructure project by the KSP.

The researcher reviews studies on the monitoring and evaluation of specific programs/projects. The following is a review of three studies.

The first study reviewed here is Firdaus's (2016) work titled "Evaluation of Social Development Projects in Community Groups of Mbeliling Forest Areas, West Manggarai Regency, NTT," which reports on an academic community of STKIP PGRI West Sumatra. The purpose of the study was to analyze the implementation of monitoring and evaluation held by the Mbeliling Community Forest Care Community Forum.

Firdaus's article has similarities with this research. Both studies concern program/project monitoring and evaluation theory on the process carried out by the institution in charge of special programs/projects. The main difference is that Firdaus's research focused on monitoring and evaluation by institutions involved in social projects. Meanwhile, this research examines the implementation of monitoring and evaluation by institutions that are authorized to monitor the running of physical projects, namely, infrastructure.

Another difference lies in the theory used in the two studies. Firdaus's research uses social project monitoring and evaluation theory, while this study uses a combination of the theory of program/project monev steps and results-based monev steps.

The second study reviewed by the researcher is "Implementation of Project Monitoring and Evaluation to Improve Project Effectiveness and Efficiency," conducted by Fransisko (2016), an alumnus of the Bandung Institute of Technology (ITB). The purpose of Fransisko's research was to analyze the causes of the weak implementation of monitoring and evaluation carried out by oil and gas companies called CINTA on the projects built by the company. The research also aimed to provide recommendations for CINTA to be able to improve the effectiveness and efficiency of monitoring and evaluation of the company's projects.

The similarity of Fransisko's study with this one is related to the analysis of the implementation of project monitoring and evaluation carried out by the responsible institution of the project. The theory used in Fransisko's research is different from the theory used here. As a research study on the implementation of monitoring and evaluation, Fransisko's research tends to use technical, managerial theories in analyzing existing problems, such as theories that are commonly used in management science. However, there was no use of theories monitoring and evaluation, which were explicitly used in the implementation of program/project monitoring and evaluation by certain institutions.

The third study was done by Fadlan (2016), an academician from Mulawarman University Samarinda, Faculty of Social and Political Sciences, State Administration Study Program. The title of the research is "Supervision and Control of District Road Infrastructure Development by the Highways Agency, Irrigation and Spatial Planning, Case Study of Paser District." The purpose of the study was to analyze the supervision and control of the construction of district road infrastructure by the Bina Marga Office, Penger, and Tata Paser Regency and to analyze the constraints in its supervision and control.

This research comes with an analysis of resultsbased program/project monev theory/projects that are refocused into appropriate program/project monitoring and evaluation steps. It is expected that the program/project monev analysis in this study can contribute knowledge to Fadlan's findings, as can be seen from the discussion of research that investigates the implementation of monitoring and evaluation of a program/project by the authorized institution. 
Overall, there are differences in the theories used in this study with the three theories reviewed by the researchers. This research utilizes the theory of resultsbased monitoring and evaluation (monev) steps to the program/project as a reference for analysis, while the theory is not used in the three studies reviewed.

The theory that contains the technical aspect of the implementation of monitoring and evaluation should be applied as an analytical framework, in an effort to observe in detail how an institution conducts monitoring and evaluation of a program. If there are problems in the implementation of the monitoring and evaluation process, this is because the institution does not comply with the rules and regulations. The researcher did not find this in the three studies reviewed. Therefore, in broad outline, this study contributes to building on the three studies by presenting an overview of the analysis of the implementation of monitoring and evaluation carried out by a particular institution on a program/project. It is expected that this study can provide useful examples/references to complement the program/project monev analysis that is found in the three studies reviewed by the researcher. The central locus of this research, which is an institution that researchers pay attention to the implementation of the monitoring and evaluation step by step, is KSP.

\section{RESEARCH METHOD}

The research method is qualitative descriptive. According to Sukmadinata (2011), qualitativedescriptive research describes existing phenomena/conditions, both natural phenomena and human-caused phenomena. Qualitative-descriptive research focuses on the characteristics along with the quality and relationship between two phenomena. Guided by this definition, this study seeks to obtain an overview related to the situation of the implementation of the KSP monitoring and evaluation function in the implementation of infrastructure/PSN. Next, the analysis uncovers the impact of the implementation of the monitoring and evaluation by KSP on infrastructure implementation.

This study uses descriptive-qualitative methods, and the research paradigm that is applied is post-positivist. Based on the characteristics of the post-positivist paradigm, an operationalization of the concept is developed to present the indicators established for the analysis. However, some indicators were not utilized, but researchers have redeveloped some of them. This research argues that indicators in concept cannot be used rigidly but need to be developed following the actual conditions necessary. The researcher adheres to the principle of objectivity in researching phenomena and, accordingly, employs the appropriate indicators that have been developed.
When viewed in terms of the benefits of research, this study is categorized as pure research. Viewed from the perspective of time, this study is cross-sectional.

In terms of data collection techniques, this research is qualitative. Data were collected through in-depth interviews and literature studies. The purpose of the indepth interviews was to obtain primary data. Then, the literature study provided secondary data.

The in-depth interviews were carried out with several sources relevant to the main issues of this study. The interview participants were as follows:

- Gibran Sesunan, Representative of the Infrastructure Team, Deputy I, Office of the Presidential Staff

- Yudha, Representative of the Infrastructure Team, Deputy I, Presidential Staff Office

- Yusuf Gumilang, Deputy Junior Expert II, Presidential Staff Office

- Ahdi and Hotma Gideon, Representatives of the Program Director of the Priority Infrastructure Acceleration Committee

- Ali Berawi, Lecturer/Lecturer of the Department of Civil Engineering, Faculty of Engineering, University of Indonesia

- Randy R. Wrihatnolo, Director of Development Systems and Reporting, Monitoring, Evaluation and Control, Ministry of PPN/National Development Planning Agency

- Ahmad Redi, Lecturer/Academician in State Constitutional Law, Law Formation of Laws, and Regulations, Environmental Law, Natural Resource Law

- Roni, Representative Director of Infrastructure Supervision, Deputy for Supervision of the Economy, Financial Supervisory Agency and Central Development

\section{ANALYSIS, RESULTS, AND DISCUSSION}

After data were collected through the in-depth interviews and literature studies, the next step was the data analysis. The analysis aimed to shed light on the implementation of the KSP monev function on the actual implementation of PSN infrastructure. Based on Miles and Huberman (2007, p. 16), the data analysis focused on three activities: data reduction, data presentation, and conclusion drawing or verification.

KSP is a government institution that is classified as a non-structural institution, which means that it is directly responsible to the President. It was established on February 23, 2015, during the administration of 
President Joko Widodo (2014-2019), to replace the position of the previous institution, namely, the Presidential Work Unit for Supervision and Control (UKP4), which operated during the regime of President Susilo Bambang Yudhoyono.

As explained previously, in general, KSP is an institution that monitors and controls national priority programs. Its duties are divided into thee tasks: managing the national priority program, political communication, and management of strategic issues.

By monitoring the national priority programs, KSP keeps them running according to the government's plan. Furthermore, KSP's political communication task is to assist the president in communicating the strategic program. It also manages the strategic issues that are considered necessary by the president. Among numerous tasks, control of the national priority program is the KSP task that is the focus of this research.

The task of controlling the national priority program is supported by three functions mandated by KSP. The three roles are the control function to ensure presidential promises are fulfilled, to resolve program problems comprehensively, and to accelerate the implementation of national priority programs.

KSP conducts monitoring through the Monitoring System, LAPOR, and field visits. Each of its monitoring tools produces a follow-up/debottlenecking of the monitoring data obtained. In terms of the debottlenecking process, KSP has carried out various efforts to unravel the blockages, such as land acquisition problems, funding problems, and coordination problems across $\mathrm{K} / \mathrm{L}$.

The National Strategic Project is a status pinned on infrastructure projects that are considered to have strategic benefits. The strategic advantages that are deemed to be achieved by boosting PSN include economic development, which can be realized by improving social welfare, strengthening national defense, and maintaining national sovereignty. As a result, to increase GDP significantly, reduce unemployment, boost socio-economic activity, and have a positive impact on the environment (KPPIP, 2019), PSN is also expected to be able to complement the existing infrastructure, which means it can add even better benefits for the future. PSN is also likely to reduce the gap in the procurement of infrastructure between regions because, with the presence of PSN, an even distribution of infrastructure can be achieved between regions (KPPIP, 2019).

National Strategic Projects should be infrastructure projects whose solutions are prioritized by the government. For example, PSN became an essential representation of infrastructure during President Joko Widodo's administration. However, the goal of realizing
PSN in five years failed. The researcher believes that President Joko Widodo was fortunate enough to win the 2019 general election. Had he lost, it would not be guaranteed that the next regime would resolve the PSN project.

Because the government program in power should be realized in the first period, the government has supported PSN since 2016. As of 2018, only 62 PSN projects were completed. With the projects completed in January to March 2019, this number rose to 75 projects, still less than half of the total attempted PSN. Thus, the implementation of PSN remains far from the government's objective.

In addition, many accidents occurred in PSN projects, proving that there were quality issues. Critics have suggested that President Joko Widodo was in a hurry to reach the PSN target. Seeing results-based monev steps, KSP should ensure that all infrastructure programs are implemented and produce benefits for the community. Yet there are still many poor indicators of results-based monitoring and evaluation.

The first dimension is that the KSP is still considered to have not performed its function in monitoring and evaluating institutions of infrastructure implementation. There are also institutions in charge monitoring and evaluating institutions focused on infrastructure project implementation, such as KPPIP. The presence of multiple institutions has created an overlap of monitoring and evaluation institutions in infrastructure development. For instance, there are other institutions such as the Directorate of SPPEPP of Bappenas and the Cabinet Secretariat, which also participated in monitoring the implementation of infrastructure. KPPIP and SPPEPP Bappenas, two monev institutions. had a mechanism for implementing monitoring and evaluation that was more comprehensive than KSP's. KPPIP oversees project management, and SPPEPP of Bappenas issues an output of monitoring and evaluation in the form of infrastructure monev report recapitulation. In terms of budget, KSP is still considered to be minimal compared to other institutions. Compared to KSP, Bappenas and KPPIP have larger budgets, plus both institutions are proven to carry out more complex and comprehensive monitoring and evaluation.

The problem is also found in the third dimension. The outcome indicators set by KSP should be the outcome indicators of the output of an infrastructure project. Nevertheless, these indicators installed by KSP are not relevant or adequate in reflecting infrastructure projects.

The fourth indicator is also not fulfilled by KSP because the data baseline of the infrastructure, as mentioned before, is not within the KSP Monitoring System. KSP cannot monitor the condition of a project 
before it is upgraded/continued by the various ministries.

Moreover, problems were found in the fifth to tenth indicators. The monitoring of inputs and outcomes by KSP seemed to have no clear basis of rules/regulations. In terms of monitoring whether or not the results of the infrastructure/PSN were achieved, KSP's performance is still in doubt. Given the news from the Director of SPPEPP Bappenas, which contradicts what was conveyed by KSP, this research found that KSP adequately monitored outcomes only on a project basis and only when there was a request from the head of KSP or the president. The process for selecting which projects will be monitored for their outcomes is still unclear because there are no standards governing it.

Then, according to the object regulations, KSP was only armed with a Presidential Regulation in its formation but did not have the legal basis for the object being tracked. The National Priority Program does not have its own Presidential Regulation. Meanwhile, when compared with the Bappenas SPPEPP, SPPEPP has Bappenas Ministerial Regulation as the legal basis for its formation and implements two government regulations, PP No. 17 of 2017 and including PP no. 39. The only legal basis that KSP has is the Presidential Regulation. This incompleteness of the legal basis of KSP has made its role unclear. In terms of identifying priority programs in the RKP to be monitored by the $\mathrm{KSP}$, there is no clear standard.

It should be stressed again that the difference in the duties of KSP and those of other institutions lies only in its monitoring mandate. KSP is only tasked with monitoring national priority programs within the RKP, while SPPEPP and Setkab monitor all the contents of the RKP, both priority and non-priority. Meanwhile, KPPIP only oversees infrastructure projects that are considered strategic and a priority by the government. For the remaining projects, there is no difference in duties between KSP, SPPEPP, and Setkab.

This research identifies that the division of tasks and authority of KSP with other M\&E implementing agencies has overlaps. There is no clarity regarding the differences in methods between KSP and other K/L monev, especially SPPEPP. Thus, the potential for data redundancy is quite enormous. As long as KSP exists, coordination between KSP and other M\&E executors and technical ministries can be maintained. However, KSP still cannot do more concrete and comprehensive infrastructure monitoring of PSN like KPPIP and SPPEPP.

\section{CONCLUSION}

KSP as the monitoring and evaluation institution for infrastructure implementation is still not perfect in implementing the results-based concept of monitoring and evaluation. There are several dimensions found problematic in its monitoring and evaluation processes. In a total of 10 dimensions, indicators that were not met were found. In Dimension 1, five indicators are not met. In Dimension 3, two indicators are not met, which can be observed in the matrix of the research results. Some indicators were not achieved due to various problems encountered by KSP, including overlapping between $\mathrm{K} / \mathrm{L}$ monev, issues of technical and management capabilities, and the lack of KSP staff to handle infrastructure monitoring and evaluation. These monev problems have ultimately led to a failure to complete the infrastructure projects according to the target.

This research makes a recommendation so that KSP can improve its monitoring and evaluation procedures following results-based theory guidelines, with the goal of resolving problems such as the ambiguity of function assignments, budget management inefficiencies, target setting, need for clarity of the legal basis for monitoring and evaluation, and staffing. The president should issue a new Presidential Regulation concerning national priority programs as transparent objects of KSP monitoring. In it, some projects should be agreed upon through the stakeholder consensus process, so there will be no more separate projects that are monitored without a foundation. All projects in the Perpres must be overseen entirely by the KSP. The contents of the Perpres are a collection of projects that are realistic to achieve as determined by various expert considerations.

If the president still wants to maintain the existence of KSP, given the KSP's position as a staff organization, the KSP's task is better minimized. It means that there is no need to conduct monitoring and evaluation with other M\&E methods. They can perform as evaluators, so there is no need to go down the field or monitor regularly, where these activities require a large budget. There is a need to increase the infrastructure team personnel to the Deputy $1 \mathrm{KSP}$, as nine people are still too few in comparison to the monev staff of other Ministries.

\section{REFERENCES}

[1] Abraha, M.W. 2009 Project monitoring and evaluation.

[2] Canning, D. dan Pedroni, P. (2004). 'The effect of infrastructure on long run economic growth' mimeograph. Harvard University, MA.

[3] Creswell 2009 Research design: qualitative, quantitative, and mixed methods approaches (3rd ed). Sage Publications, Thousand Oaks, CA.

[4] Gorgens, M. and Zall Kusek, J. (2010). 'Making monitoring and evaluation systems work: a capacity development toolkit'. (English). World Bank, Washington, DC. 
[5] Gosling, L. and Edwards, M. (2009). 'Toolkits: A practical guide to assessment, monitoring' [Review], and Evaluation. Save the Children, London.

[6] Greene and Jennifer. (n.d.). 'Qualitative program evaluation: practise and promise, in Norman K. Denzin and Yvonna S. Lincoln (eds)' A handbook of qualitative research. Califonia: solid action on globalization and environment Publications Inc, Thousand Oaks.

[7] Grigg, N. 1988 Infrastructure engineering and management. John Wiley \& Sons, Chichester.

[8] Gudda, P. 2011 A guide to project monitoring \& evaluation, Nairobi: AuthorHouse.

[9] Hasibuan 2010 Manajemen sumber daya manusia. Bumi Aksara, Jakarta.

[10] HENNER, H.-F. 2000 Infrastructure et développement un bilan.

[11] international fund for agriculture development 2002 A guide for project monitoring and evaluation. International Fund for Agricultural Development.
[12] Khan, A.M. 2001 A guidebook on results-based monitoring and evaluation: key concepts, issues, and applications. Sri Lanka: monitoring and Progress Review Division. Ministry of Plan Implementation.

[13] Kodoatie, R.J. 2005 Pengantar manajemen Infrastruktur, [Yogyakarta: Pustaka pelajar].

[14] Kohli, U.T. and Chitkara, K.K. 2008 Kohli, U. Project management handbook. Tata McGraw-Hill Publishing company Limited, New Delhi, India.

[15] Kusek, J.Z. and Rist, R.C. 2004 Ten steps to a results-based monitoring and evaluation system: A handbook for development practitioners. World Bank, Washington, DC.

[16] Pazvakavambwa, A. and Steyn, G.M. (2014). 'Implementing results-based management in the public Sector of Developing Countries: what should be considered?' Mediterranean Journal of Social Sciences, 5(20), p. 245. https://doi.org/10.5901/mjss.2014.v5n20p245.

[17] School of Geography \& Environment, Oxford University 2014 Step by step guide to monitoring and evaluation. Oxford University, Oxford. 